\title{
Impact of Social Support on Subjective Oral Health Status among Elderly People
}

\author{
Eunsuk Ahn', Jin-Ha Lee ${ }^{2}$, and Sun-Mi Kim ${ }^{3, \dagger}$ \\ 'Department of Dental Hygiene, Daejeon Institute of Science and Technology, Daejeon 35408, \\ ${ }^{2}$ Department of Dental Hygiene, Kyungbok University, Pocheon 11138, \\ ${ }^{3}$ Department of Dental Hygiene, Wonkwang Health Science University, Iksan 54538, Korea
}

\begin{abstract}
Background: Owing to the increase in the aging population, the health problems of the elderly have become important social problems. Social support has a positive effect on improving the quality of life and prolonging the life of elderly people. It is one of the major factors that affects the oral health status of elderly people. The purpose of this study was to examine the relationship between oral health status and social support in elderly people using representative data.

Methods: In this study, data from a community health survey in 2015 involving 63, 929 elderly people aged over 65 years were analyzed. T-test and ANOVA analyses were performed to compare the general characteristics of and perception about social support. Additionally, a linear regression analysis was performed to confirm the relationship between perceptions about social support and subjective oral health status.

Results: We found that sex, age, household income, education level, the presence of a spouse, existence of an unmet dental need, and regular oral check-up had a significant effect on subjective oral health status $(p<0.05)$. In addition, when controlled for all factors, social support has a significant impact on subjective oral health status.

Conclusion: The findings indicate that social support is associated with the subjective oral health status of Korean elderly. This suggests that community-level or government investment is required to improve the oral health of the elderly. In particular, policy interventions such as the establishment of facilities that promote social networks, especially facilities based on friendship networks, are needed.
\end{abstract}

Key Words: Aged, Oral health, Social support

\section{Introduction}

The health problems of the elderly are indisputably biological and sociological. Health is influenced by the social environment, and health problems result in social problems ${ }^{1,2)}$. Health problems associated with aging include the decline of physical function and social and psychological deterioration, which is an economic burden. Integrated health care is very important for elderly people with chronic diseases ${ }^{3,4)}$. Health care is an important positive variable for social support and self-esteem. It is an important factor for maintaining physical and psychological health $^{5-8)}$. Social support refers to a series of actions aimed at satisfying an individual's physical, material, and emotional needs through the individuals' relationships with those around them ${ }^{9}$. Social support, which involves interaction with others, and self-esteem, which has to do with valuing one's self, are components of health care in terms of personal and social integration, and experiences through support in the relationship between the environment and others ${ }^{2,10)}$. Social support improves the quality of life and prolongs the life of the elderly and is seen as one of the major factors that affects the health status of the elderly ${ }^{2,9,11)}$. 
Oral health problems among the elderly are a major health problem. Oral health problems result in weakened teeth and high tooth loss rate. Additionally, the oral condition of elderly people is relatively poor than that of individuals in other age groups ${ }^{12-14)}$. In particular, elderly people with low socioeconomic status experience social disconnection due to social isolation and alienation and the deterioration of their health and quality of life. Dental problems that require treatment seem to diminish one's value and importance ${ }^{15,16)}$. Social support and socioeconomic characteristics are considered fundamental determinants of oral health because they can affect proximal risk factors for oral disease, such as developing oral health-related behaviors and modifying lifestyles ${ }^{17,18)}$. There is little research on the relationship between oral health and social support in Korea. The purpose of this study was to identify the relationship between oral health and social support in elderly people using representative data. We hope to provide basic data for the development of oral health policies for the elderly who experience social isolation frequently.

\section{Materials and Methods}

\section{Research subjects}

This study used Community Health Survey data from the Korea Centers for Disease Control and Prevention.
The Community Health Survey is a survey to examine the health status and behavior of citizens over 19 years old to provide adequate data for the development of evidencebased health projects in the region. This survey includes items such as health, mental health, oral health, social support, and general characteristics. In this study, data from a Community Health Survey in 2015 involving 63,929 elderly people aged over 65 years were analyzed.

\section{Research variables}

In this study, the subjective oral health status, measured on a 5-point Likert scale, was used as the dependent variable. The higher the social support score, the more positive the perception of social support. Social support items were measured on a 5-point Likert scale. The score was then averaged and used for analysis. As independent variables, social support variables were calculated using the sex, age, household income, education level, Existence of spouse, oral healthcare behavior (regular oral check-up, existence of an unmet dental need), and social support questions (Table 1).

\section{Analysis methods}

The general characteristics of the study subjects were investigated using frequency analysis. The t-test and one-way ANOVA were performed to compare the differences in the perceptions of social support according

Table 1. Study Variable

\begin{tabular}{|c|c|}
\hline Classification & Detail \\
\hline \multicolumn{2}{|l|}{ Dependent variable } \\
\hline Subjective oral health & $1=$ very poor, $2=$ poor, $3=$ medium, $4=$ good, $5=$ very good \\
\hline \multicolumn{2}{|l|}{ Independent variable } \\
\hline Sex & $1=$ male, $2=$ female \\
\hline Age $(y)$ & $1=65 \sim 74,2=\geq 75$ \\
\hline Household income per monthly (thousand won) & $1=\leq 50,2=\geq 50 \sim 100,3=\geq 101 \sim 200,4=\geq 201$ \\
\hline Education level & $1=\leq$ elementary and below, $2=\geq$ middle school and above \\
\hline Existence of spouse & 1=living together, 2 =living apart, bereavement, divorce, unmarried \\
\hline Regular oral check-up & $1=$ yes, $2=$ no \\
\hline Unmet dental need & $1=$ yes, $2=$ no \\
\hline \multirow[t]{6}{*}{ Social support (5-point Likert scale) } & Can you trust and rely on each other in your neighborhood? \\
\hline & Are you satisfied with the natural environment in your neighborhood? \\
\hline & Are you satisfied with the living environment in your neighborhood? \\
\hline & Are you satisfied with the health care delivery system in your neighborhood? \\
\hline & How often do you see or communicate with the relatives (family) you contact the most? \\
\hline & How often do you see or contact the neighbors you contact the most? \\
\hline
\end{tabular}


to the general characteristics. Bonferroni post-hoc tests were conducted to confirm significant differences between groups. Finally, linear regression analysis was conducted to confirm the relationship between the subjective oral health level, general characteristics, and social support. For all analysis, STATA software version 11.0 (Stata Corp., College Station, Tx, USA) was used, and the statistical significance level was set at 0.05 .

\section{Results}

\section{General characteristics of research subjects}

The general characteristics of the study subjects are shown in Table 2. According to sex, 59.12\% were females and $40.88 \%$ were males. Additionally, $57.13 \%$ of the subjects were young elders with ages ranging from $65 \sim$ 74 years and the remaining $42.87 \%$ were old elders who were 75 years or older. The average monthly household income was $30.97 \%$ with more than $51 \sim 100$ thousand won being the highest. With regard to education level, only $66.02 \%$ of subjects attended elementary school. With

Table 2. Distribution and Rate of Study Subjects

\begin{tabular}{lc}
\hline \multicolumn{1}{c}{ Variable } & $\mathrm{n}(\%)$ \\
\hline Sex & \\
Male & $26,134(40.88)$ \\
Female & $37,795(59.12)$ \\
Age $(\mathrm{y})$ & \\
$\quad 65 \sim 74$ & $36,521(57.13)$ \\
$\geq 75$ & $27,408(42.87)$ \\
Household income per monthly (thousand & \\
$\leq 50$ & $15,028(23.70)$ \\
$\geq 51 \sim 100$ & $19,640(30.97)$ \\
$\geq 101 \sim 200$ & $13,449(21.21)$ \\
$\geq 201$ & $15,296(24.12)$ \\
Education level & \\
$\leq$ Elementary school & $42,156(66.02)$ \\
$\geq$ Middle school & $21,699(33.98)$ \\
Existence of spouse & \\
Yes & $39,710(62.15)$ \\
No & $24,179(37.85)$ \\
Regular oral check-up & \\
Yes & $12,663(19.82)$ \\
No & $51,221(80.18)$ \\
Yes & \\
No & \\
& \\
\hline & \\
&
\end{tabular}

regards to oral care, $80.18 \%$ of the subjects did not attend regular oral check-ups, and $19.48 \%$ of subjects had an existing unmet dental need.

\section{Social support perception according to the general characteristics}

The general characteristics and social support perception of subjects are presented in Table 3. The score of the younger elderly was 3.19, which was higher than that of the older elderly (3.10; $\mathrm{p}<0.05)$. Additionally, as household income increased, social support increased significantly $(p<0.05)$. Moreover, the presence of a spouse significantly affected the perception of social support $(\mathrm{p}<0.05)$.

\section{Factors affecting subjective oral health status}

The results of the linear regression analysis to confirm the effect of social support on subjective oral health status are presented in Table 4. Sex, age, household income, education level, presence of a spouse, existence of an unmet dental need, regular oral check-up, and social

Table 3. Differences in Social Support and General Characteristics

\begin{tabular}{lccc}
\hline \multirow{2}{*}{ Variable } & \multicolumn{3}{c}{ Social support } \\
\cline { 2 - 4 } & $\begin{array}{c}\text { Mean } \pm \text { estimated } \\
\text { standard deviation }\end{array}$ & $\mathrm{t} / \mathrm{F}$ & $\mathrm{p}$-value \\
\hline Sex & $3.14 \pm 0.75$ & -3.20 & $<0.001$ \\
$\quad$ Male & $3.16 \pm 0.71$ & & \\
$\quad$ Female & & 16.32 & $<0.001$ \\
Age & $3.19 \pm 0.74$ & & \\
$\quad 65 \sim 74$ & $3.10 \pm 0.70$ & & \\
$\quad \geq 75$ & & 156.48 & $<0.001$ \\
Household income per & & & \\
monthly (thousand won) & & & \\
$\quad \leq 50$ & $3.06 \pm 0.70$ & & \\
$\quad \geq 51 \sim 100$ & $3.15 \pm 0.70^{\mathrm{a}}$ & & \\
$\quad \geq 101 \sim 200$ & $3.20 \pm 0.73^{\mathrm{b}}$ & & \\
$\quad \geq 201$ & $3.21 \pm 0.76^{\mathrm{c}}$ & & \\
Education level & & -12.92 & $<0.001$ \\
$\quad \leq$ Elementary school & $3.13 \pm 0.69$ & & \\
$\quad \geq$ Middle school & $3.21 \pm 0.78$ & & \\
Existence of spouse & & 19.74 & $<0.001$ \\
$\quad$ Yes & $3.20 \pm 0.72$ & & \\
$\quad$ No & $3.08 \pm 0.73$ & & \\
\hline
\end{tabular}

Data are analysed by t-test and one-way ANOVA statistics.

${ }^{\mathrm{a}-\mathrm{c}}$ The same letter indicates no significant difference by Bonferroni. 
Table 4. Factors Influencing Subjective Oral Health

\begin{tabular}{|c|c|c|c|c|}
\hline Variable & Coef. & SE & $\mathrm{t}$ & p-value \\
\hline \multicolumn{5}{|l|}{ Sex } \\
\hline Male & (Ref.) & & & \\
\hline Female & 0.09 & 0.01 & 10.54 & $<0.001$ \\
\hline \multicolumn{5}{|l|}{ Age } \\
\hline $65 \sim 74$ & (Ref.) & & & \\
\hline$\geq 75$ & -0.19 & 0.01 & -23.70 & $<0.001$ \\
\hline \multicolumn{5}{|c|}{ Household income per monthly (thousand won) } \\
\hline$\leq 50$ & (Ref.) & & & \\
\hline$\geq 51 \sim 100$ & 0.06 & 0.01 & 5.46 & $<0.001$ \\
\hline$\geq 101 \sim 200$ & 0.12 & 0.01 & 10.36 & $<0.001$ \\
\hline$\geq 201$ & 0.16 & 0.01 & 14.23 & $<0.001$ \\
\hline \multicolumn{5}{|l|}{ Education level } \\
\hline$\leq$ Elementary school & (Ref.) & & & \\
\hline$\geq$ Middle school & 0.20 & 0.01 & 22.96 & $<0.001$ \\
\hline \multicolumn{5}{|l|}{ Existence of spouse } \\
\hline Yes & (Ref.) & & & \\
\hline No & -0.07 & 0.01 & -7.35 & $<0.001$ \\
\hline \multicolumn{5}{|l|}{ Regular oral check-up } \\
\hline No & (Ref.) & & & \\
\hline Yes & 0.15 & 0.01 & 16.30 & $<0.001$ \\
\hline \multicolumn{5}{|l|}{ Unmet dental need } \\
\hline No & (Ref.) & & & \\
\hline Yes & -0.48 & 0.01 & -51.68 & $<0.001$ \\
\hline Social support & 0.13 & 0.01 & 25.45 & $<0.001$ \\
\hline Constant & 1.85 & 0.03 & 59.20 & $<0.001$ \\
\hline
\end{tabular}

Data are analysed by multiple linear regression statistics.

Coef.:coefficient, SE:standard errors, Ref.: reference.

support were found to have a significant effect on subjective oral health status $(p<0.05)$. In particular, when all factors were adjusted, subjective oral health status increased as social support score increased. The subjective oral health score increased by 0.13 points each time the social support score increased by 1 point, regardless of the socioeconomic status of the elderly. The explanatory power of the regression model was $11.0 \%$.

\section{Discussion}

This is one of the first studies to explore the link between social support and oral health in elderly people nationwide. The data used in this study are representative of the national perspective. The data were obtained from a large population and have undergone representative sampling processes ${ }^{19)}$.

Among the elderly, the difference in perception of social support according to sex was statistically significant. According to age, the perception of social support was lower among the older elderly people than among the younger elderly people. This is owing to the decrease in the frequency of contact with children and siblings ${ }^{20)}$. In general, the size of social networks and the frequency of social exchanges decrease with age ${ }^{2,5,8)}$. This is because physical and mental activities are more limited as one ages. In this study, the higher the household income and education levels, the higher the recognition of social support. The results are consistent with those of previous studies. Elderly people with high socioeconomic status may be more economically active than those with low socioeconomic status. Accordingly, it is thought that social support is highly recognized when people participate more actively in social activities ${ }^{17,18)}$. Additionally, the perception of social support among elderly people with spouses was higher. This is consistent with the results of 
previous studies that reported that elderly people without spouses had weaker social relations than those with spouses $^{2)}$. This finding suggests that elderly people without spouses need practical intervention in order to form and maintain supportive friendships. As a result, social support alleviates the stress of older people and provides specific protection and support. In addition, it can be seen that it not only improves immunity to disease, but also maximizes adaptability and resilience, affecting psychological well-being ${ }^{20-22)}$. The higher the education level of the elderly, the more positive their subjective oral health status. Among the elderly, the level of education adequately reflects changes in past socioeconomic positions and generally affects the subjective oral health status ${ }^{3,14,18)}$. These findings are thought to be due to the fact that the lower the economic and educational levels, the greater the risk of oral health problems, and the lower the accessibility to medical information and health care. In addition, elderly people with spouses had higher subjective oral health levels than those without spouses. This is because elderly people who live alone feel alienated and lonely when they do not receive the support of their family members; hence, their physical, mental, and social health conditions deteriorate ${ }^{20,21)}$.

After adjusting for sociodemographic factors (such as sex, age, education level, and household income) and oral health behavioral covariates that are known to affect subjective oral health status, social support was found to be significantly associated with the subjective oral health status $^{17,18)}$. This result suggests that social support influences the subjective oral health status of elderly people ${ }^{1,21-23)}$. In general, socioeconomic factors and oral health behaviors are considered the main factors that affect oral health ${ }^{22,24)}$. Even when these major factors have been adjusted and examined, the effect of social support on subjective oral health was still significant. While poverty has a negative health effect, even among the poor, this negative effect may be alleviated if social support is provided $^{24)}$. Therefore, in addition to improving the economic status, efforts should be made to recognize the importance of social support and to provide a formal social support system through community linkage and social welfare programs. In addition, among elderly people, the role of social support can become increasingly important in relation to the additional need of time, resources, and policies for the oral health care of the community system $^{1,9,23)}$. During old age, factors that negatively affect social support increase because of the decrease in economic power due to retirement, decrease in physical ability, and death of a spouse. As these factors increase, social support is likely to decrease, which may have a negative impact on health ${ }^{5,11,22)}$. Moreover, these factors can have a direct negative effect on health ${ }^{18,20,21)}$. Our results emphasize the need for community level action or governmental investment to establish amenities that promote the building of social capital, especially that related on friendship networks. In conclusion, social support is associated with self-reported oral health status among Korean elderly. Obviously, the interdependence of social support and the oral health of elderly people should not be underestimated and should be further investigated.

\section{Notes}

\section{Conflict of interest}

No potential conflict of interest relevant to this article was reported.

\section{Ethical approval}

This study was approved by Institutional Review Board of the Daejeon Institute of Science and Technology (IRB2019-003-017).

\section{Author contributions}

Conceptualization: Eunsuk Ahn. Data acquisition: Eunsuk Ahn, Sun-Mi Kim. Formal analysis : Eunsuk Ahn, Jin-Ha Lee. Supervision: Eunsuk Ahn, Sun-Mi Kim. Writing-original draft: Eunsuk Ahn, Jin-Ha Lee, Sun-Mi Kim. Writing-review \& editing: Sun-Mi Kim.

\section{ORCID}

Eunsuk Ahn, https://orcid.org/0000-0002-9404-4826

Jin-Ha Lee, https://orcid.org/0000-0002-3062-8216

Sun-Mi Kim, https://orcid.org/0000-0003-0718-9419 


\section{References}

1. Gironda MW, Maida C, Marcus M, Wang Y, Liu H: Social support and dental visits. J Am Dent Assoc 144: 188-194, 2013.

https://doi.org/10.14219/jada.archive.2013.0098

2. Eom A, Lee Y, Choi H: Relation between social support and health status in elderly. J Korean Gerontol Nurs 8: 136-145, 2006.

3. Lim KC, Kim S: Prevalence and correlates of depression in older Koreans: comparison of young-old and old-old. J Korean Acad Psychiatr Ment Health Nurs 21: 1-10, 2012. https://doi.org/10.12934/jkpmhn.2012.21.1.1

4. Lee I: Development of a community-based preventive health care model for the elderly in Korea through the evaluation of a Japanese counterpart. Perspect Nurs Sci 7: 10-22, 2010.

5. Kim OH: Analysis of effects which social supports and cohabiting influence on the elderly's mental health. Soc Sci Stud 22: 235-256, 2013.

6. Han SY, Han YK: Effects of social support, sleep quality, and oral health impact profile on depression among pregnant women. J Dent Hyg Sci 17: 134-141, 2017. https://doi.org/10.17135/jdhs.2017.17.2.134

7. Koo SS, Jung $\mathrm{OH}$, Jang SH: The relationships of ego-identity, social support and mental health of adolescents. J Korea Contents Assoc 11: 225-237, 2011. https://doi.org/10.5392/JKCA.2011.11.9.225

8. Yoo YG, Ko SH, Kim KB, Chung SH: Effects of perceived social support on self esteem in elderly. J Korean Acad Adult Nurs 16: 102-110, 2004.

9. Rosario AM, Pérez-Stable EJ: Making neighborhoods good for your health. Circulation 134: 514-516, 2016. https://doi.org/10.1161/CIRCULATIONAHA.116.024158

10. Qiu RM, Tao Y, Zhou Y, Zhi QH, Lin HC: The relationship between children's oral health-related behaviors and their caregiver's social support. BMC Oral Health 16: 86, 2016. https://doi.org/10.1186/s12903-016-0270-4

11. de Araújo SSC, de Lima Freire DB, Padilha DMP, Baldisserotto J: Social support, health and oral health promotion in the elderly population in Brazil. Interface 10: 203-216, 2006. https://doi.org/10.1590/S1414-32832006000100014

12. Allen PF: Association between diet, social resources and oral health related quality of life in edentulous patients. J Oral Rehabil 32: 623-628, 2005.

https://doi.org/10.1111/j.1365-2842.2005.01488.x

13. Locker D, Gibson B: Discrepancies between self-ratings of and satisfaction with oral health in two older adult populations. Community Dent Oral Epidemiol 33: 280-288, 2005. https://doi.org/10.1111/j.1600-0528.2005.00209.x

14. Brennan DS, Singh KA: General health and oral health self-ratings, and impact of oral problems among older adults. Eur J Oral Sci 119: 469-473, 2011. https://doi.org/10.1111/j.1600-0722.2011.00873.x

15. Kim CS, Paik DI, Kim HD, Jin BH, Bae KH: The oral health care needs among elderly people with daily activity problems in Yongin city. J Korean Acad Oral Health 31: 559-567, 2007.

16. Ahn E, Hwang J, Shin M: Dental utilization associated factors among elderly. J Dent Hyg Sci 15: 60-66, 2015. https://doi.org/10.17135/jdhs.2015.15.1.60

17. Locker D: Deprivation and oral health: a review. Community Dent Oral Epidemiol 28: 161-169, 2000. https://10.1034/j.1600-0528.2000.280301.x

18. Watt RG: Emerging theories into the social determinants of health: implications for oral health promotion. Community Dent Oral Epidemiol 30: 241-247, 2002. https://doi.org/10.1034/j.1600-0528.2002.300401.x

19. Kim YT, Choi BY, Lee KO, et al.: Overview of Korean community health survey. J Korean Med Assoc 55: 74-83, 2012.

https://doi.org/10.5124/jkma.2012.55.1.74

20. Kim SA: Impact of family support and social support on hopelessness among rural elderly people. J Agric Ext Community Dev 19: 581-616, 2012. https://doi.org/10.12653/jecd.2012.19.3.581

21. Aida J, Kuriyama S, Ohmori-Matsuda K, Hozawa A, Osaka $\mathrm{K}$, Tsuji I: The association between neighborhood social capital and self-reported dentate status in elderly Japanese the Ohsaki cohort 2006 study. Community Dent Oral Epidemiol 39: 239-249, 2011. https://doi.org/10.1111/j.1600-0528.2010.00590.x

22. McGrath C, Bedi R: Influences of social support on the oral health of older people in Britain. J Oral Rehabil 29: 918-922, 2002 .

https://doi.org/10.1046/j.1365-2842.2002.00931.x 
23. Rouxel PL, Heilmann A, Aida J, Tsakos G, Watt RG: Social capital: theory, evidence, and implications for oral health. Community Dent Oral Epidemiol 43: 97-105, 2015. https://doi.org/10.1111/cdoe.12141
24. Kim J, Won S: The impact of late-life poverty on self-rated health: a mediated moderation model of health behaviors and social support. J Korea Gerontol Soc 31: 463-478, 2011. 